\title{
Pilot Study on Effectiveness of Structured Teaching Programme Knowledge and Practice of Postnatal Mothers Regarding Essential Newborn Care in Selected Community Areas of Vishakhapatnam, Andhra Pradesh
}

Author(s):Lavanya.U, phD Scholar, Department of Nursing, Himalayan University, Arunachal pradesh, India and Email ID: lavanya-uriti@gmail.com

Dr.Rajina Rani, Himalayan University, Arunachal Pradesh, India, Email ID: rajina.sahul@yahoo.com

ABSTRACT: The aim of the study was to assess the knowledge and practice of post natal mothers regarding essential newborn care at Vishakhapatnam. The analysis of the study made based on findings obtained from descriptive and inferential statistical analysis. The study findings revealed that there is no significant difference between the knowledge and practice of postnatal mothers regarding essential newborn care.

\section{I.INTRODUCTION}

"A newborn baby is like the beginning of all things - Wonder, hope, a dream of possibilities".

\section{- Eda.Leshas}

The birth of a baby is one of life's most wondrous moments, babies have amazing abilities. Yet they are completely depended on others for feeding, warmth and comfort. Newborn is a continuum of the fetal life and very important transient time to adopt extra uterine life. The physical and mental wellbeing of every individual depends on the correct management of events in perinatal period. (Stephon W Elizabeth, 2004).

The newborn's body is the most super sensitive, delicate and susceptible from which can easily harmed if not taken care of. To ensure that the body has the best possible start in life there are critical aspects of newborn care, which all birth attendants and families should be aware of.

Environmental temperature should be maintained according to baby weight and age to avoid hypothermia. It is necessary to dry up the baby and wrap the baby with clothes make sure the baby head is covered (Dutta. P, 2008).

Newborn or neonatal period include the time from birth to 28 days of life. This is the crucial period in laying the foundation of good health. At this time specific biological and psychological needs must be met to ensure the survival and health development of the child into a future adult. (Hocken Berry \& Wilson 2005).

The principles of essential newborn care is simple, requiring no expensive high technology equipment resuscitation, warmth to avoid hypothermia, early breast feeding, hygiene, support for the mother ${ }^{\text {infant }}$ relationship and early treatment for low birth weight or sick infants (Hocken Berry and Wilson, 2005).

The first week of life is the most crucial period in the life of an infant. This is because the newborn has to adapt itself rapidly and successfully to an alien external environment. The risk of death is greatest during the first 24-48 hours after birth. Newborn morality is one of the most neglected health problems in the developing world, there are estimated 4 million neonatal deaths worldwide each year. Moreover, it is estimated to account for $40 \%$ of under five deaths and two-third of infant deaths. The proportion is generally higher in rural areas. According to World Health Report 2005, global neonatal mortalities rate is $36 / 1000$, while in developing counties, the rate is 39/10006.(Belsey M 2000).

Poor perinatal and neonatal care is responsible for many deaths even during later childhood. They also account for mental retardation and other neurological handicaps of later life which are largely preventable. Improved neonatal care lead a better and intact infant survival, which will pave the way for better acceptance of 
small family norm. Mother plays a key role in identifying minor developmental deviations and early evidence of disease process because she is constantly and closely watching her baby. Participation of mother in the nursing care of baby infuses self confidence in her and reduces demands on nursing personnel. So she needs the basic knowledge and skills pertaining to child feeding, personal hygiene, immunization and other common problems in children.

India's current neonatal mortality is higher in rural areas at 49/1000 live births than in urban area at 27/1000 live births. Orissa have the highest neonatal mortality rate of 61/1000 live births. Karnataka, Uttar Pradesh, Madhya Pradesh, West Bengal, Punjab have the neonatal mortality rate of 54/1000, 53/1000, 51/1000, 31/1000, 29/1000 live births respectively. Kerala have the lowest neonatal mortality of 10/1000 live births respectively. It is necessary together to meet both national and the millennium development goal to reduce Neonatal Mortality rate by two thirds between 1990 and 2015. In India, Andhra Pradesh stands 6 place in neonatal mortality rate of 30/1000 live births. (WHO 2011).

The risk of neonatal mortality is more acute in rural areas where expert obstetric care is scarce, and the home environmental conditions in which the baby is born, are usually unsatisfactory. Roughly $60 \%$ of birth in less developed counties occurred at home, so parents need to be educated about what they can do to save their newborn lives. Families need to adapt better nutritional practices, including breastfeeding ; learn how to dry and warm their newborns; and better understand the danger signs of maternal and neonatal complication saving newborn lives depends on a broad based condition that include donors and international organizations that can provide policy focus and finding, governments that are willing to expand their commitment to national and local health care services, and NGOs and gross roots organizations that can work with communities to pass on information on saving newborns (Park. K, 2007).

The challenges of reducing neonatal mortality require solutions through research to inform programme innovation and action-oriented policies designed to improve newborn health. In all these above programmes, the mother plays a vital role. The community health nurse can educate the mothers regarding essential new born care and regarding antenatal care and postnatal care and regarding importance of institutional deliveries and through proper guidance and education regarding essential newborn care (Benny. W. Elizabeth, 2004).

Since mothers are the primary care takers of the newborns round the clock, it is the most important priority to improve their knowledge and competency. If a mother is educated, she can educate the entire family and the community as well.

\section{EXPERIMENTAL WORK}

Aexperimental study was conducted to assess the knowledge and practice of postnatal mothers regarding essential newborn care at Vishakhapatnam..

Research Design: Quasi - experimental one group pretest and post test experimental research design and the approach of quantitative experimental in nature.

Setting:Bheemunipatnam, Vishakhapatnam, Andhra Pradesh .

Population: postnatal mothersof selected community areas of vishakhapatnam.

Sample size: 20 postnatal mothers .

Sample technique:purposive sampling technique.

Criteria for sample selection:

- Postnatal mothers at Visakhapatnam.

- Mothers who are willing to participate in this study

- Mothers who are able to communicate freely in Telugu/English

- Mothers who are at the age group 20-35 years

- Mothers of any level of education. 
The study is carried out by using structured questionnaire on essential newborn care under three sections I,II, \& III.

Section I: Deals with the demographic variables such age of mother, educational status, religion, monthly income, type of delivery, parity, age of the child,sex of the child,weight of the child..

Section II: Deals with knowledge regarding essential newborn care.

$>$ It consists of 15 multiple choice questions to assess the knowledge regarding essential new born care. Each question has 4 options in which one option correct and other 3 options are wrong. Each correct answer carries one mark, wrong answer carries zero mark.

Section III: :Deals with practice regarding essential newborn care

$>$ It consists of 15 questions to assess the practice of essential new born care among postnatal mothers. Both positive and negative questions are formed based on observational check list.

Score Interpretation: The total score was 30

The knowledge scores are categorized into three groups.
$0-50 \%$
$51-75 \%$
inadequate knowledge( $0-15)$
$>75 \%$
Moderately knowledge(16-20)
Adequate knowledge (21-30)

The practice scores are categorized into three groups.
$0-50 \%$
inadequate knowledge( 0-6)
$51-75 \%$
- $\quad$ Moderately knowledge(7-9)
$>75 \%$
- $\quad$ Adequate knowledge (10-15)

Overall knowledge and practice scores are categorized into three groups.

$0-50 \%$

$$
\begin{aligned}
& 51-75 \% \\
& >75 \%
\end{aligned}
$$

- $\quad$ inadequate knowledge( $0-15)$

- $\quad$ Moderately knowledge(16-23)

- $\quad$ Adequate knowledge (24-30)

\section{Table - I}

\section{RESULTS AND DISCUSSIONS}

Frequency and percentage Distribution of level of knowledge and practice regarding essential newborn care among postnatal mothers in the pretest

$\mathbf{n = 2 0}$
\begin{tabular}{|l|l|l|l|l|l|}
\hline $\begin{array}{l}\text { Inadequate } \\
(<50 \%)\end{array}$ & \multicolumn{2}{l}{$\begin{array}{l}\text { Moderate } \\
\mathbf{7 5 \%})\end{array}$} & $\begin{array}{l}\text { (50\% } \\
\text { Fdequate } \\
(>50 \%)\end{array}$ \\
\hline $\mathbf{F}$ & $\%$ & $\mathrm{~F}$ & $\%$ & $\mathrm{~F}$ & $\%$ \\
\hline 11 & $5.5 \%$ & 6 & $3 \%$ & 3 & $1.5 \%$ \\
\hline 10 & $5 \%$ & 8 & $4 \%$ & 2 & $1 \%$ \\
\hline 11 & $5.5 \%$ & 7 & $3.5 \%$ & 2 & $1 \%$ \\
\hline
\end{tabular}

Table -1 shows the level knowledge, practice and overall knowledge and practice among postnatal mothers regarding essential newborn care 11(5.5\%), 10(5\%), 11(5.5\%) had inadequate knowledge, $6(3 \%), 8(4 \%), 7($ $3.5 \%)$ had moderate knowledge and $3(1.5 \%), 2(1 \%), 2(1 \%)$ had adequate knowledge the pre assessment level of knowledge and practice. 


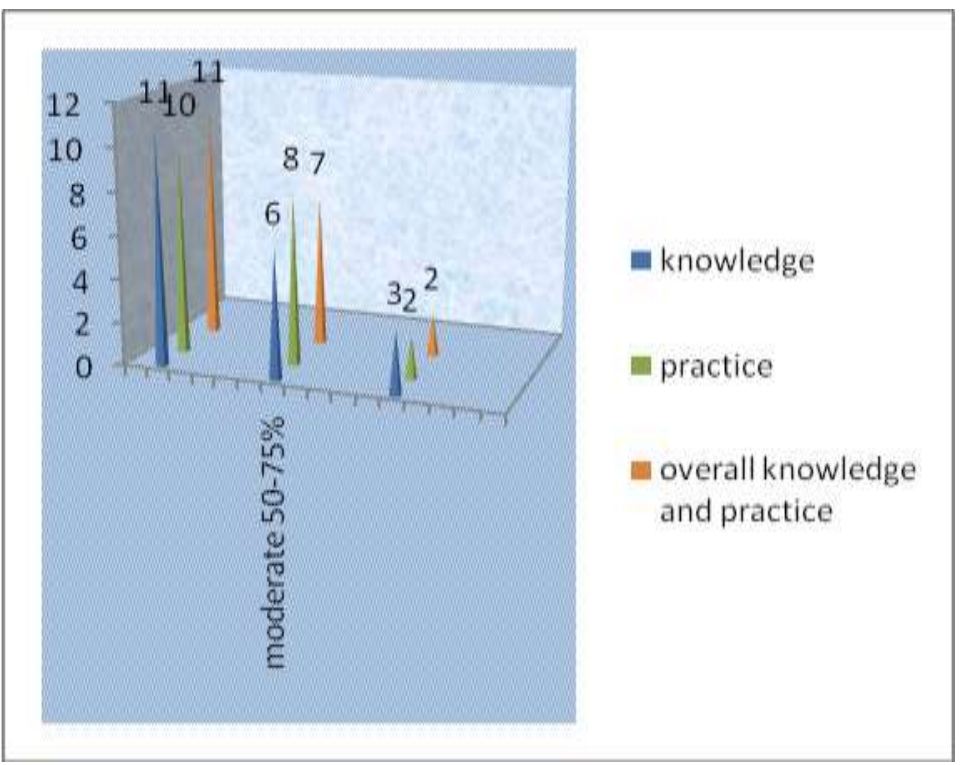

Fig.IPercentage distribution level of knowledge and practice related to essential newborn care among postnatal mothers in the pretest.

\section{Table II}

Frequency and percentage Distribution of level of knowledge and practice regarding essential newborn care among postnatal mothers in the post- test

n=20
\begin{tabular}{|l|l|l|l|l|l|}
\hline $\begin{array}{l}\text { Inadequate } \\
(<50 \%)\end{array}$ & \multicolumn{2}{l}{$\begin{array}{l}\text { Moderate } \\
\mathbf{7 5 \%})\end{array}$} & $\begin{array}{l}\text { (50\% } \\
\text { Adequate } \\
(>75 \%)\end{array}$ \\
\hline $\mathbf{F}$ & $\%$ & $\mathrm{~F}$ & $\%$ & $\mathrm{~F}$ & $\%$ \\
\hline 3 & $1.5 \%$ & 7 & $3.5 \%$ & 12 & $6 \%$ \\
\hline 2 & $1 \%$ & 8 & $4 \%$ & 10 & $5 \%$ \\
\hline 1 & $0.5 \%$ & 5 & $2.5 \%$ & 14 & $\mathbf{7 \%}$ \\
\hline
\end{tabular}

Table -1I shows the level knowledge, practice and overall knowledge and practice among postnatal mothers regarding essential newborn care 3(5.5\%), 2(5\%), 1(5.5\%) had inadequate knowledge, 7 (3\%), $8(4 \%), 5($ $4 \%)$ had moderate knowledge and 12(6\%),10 (5\%),14 (7\%) had adequate knowledge the post assessment level of knowledge and practice. 


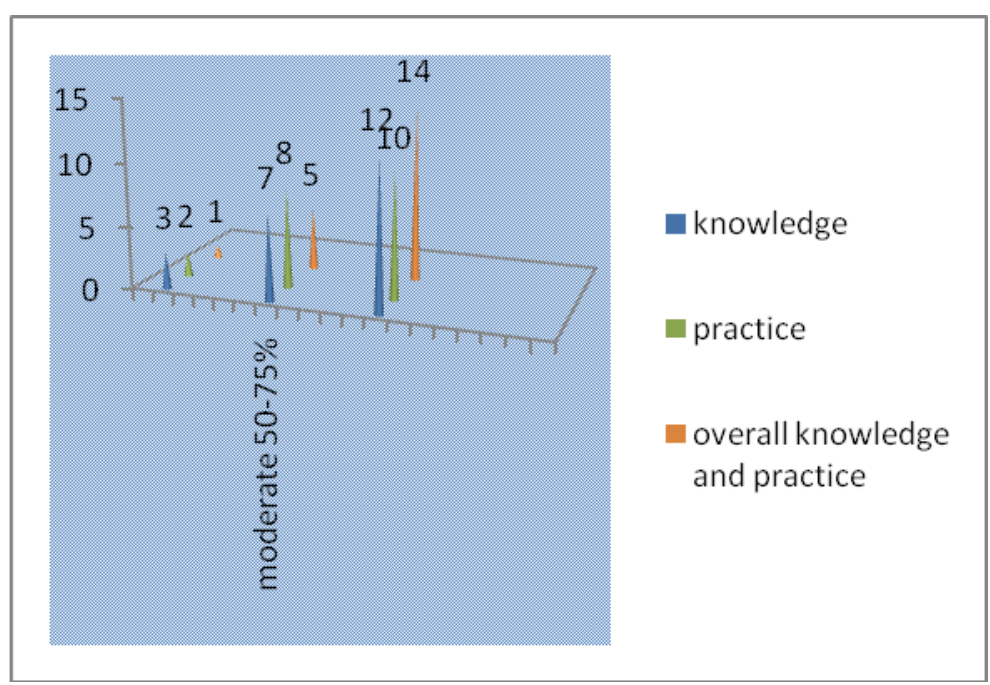

Fig IIPercentage distribution level of knowledge and practice related to essential newborn care among postnatal mothers in the post test.

Table - III

Effectiveness of structured teaching programme on essential new born care among post natal mothers. $\mathbf{n}=\mathbf{2 0}$

\begin{tabular}{|l|l|l|l|l|l|}
\hline \multirow{2}{*}{ Variable } & \multicolumn{3}{|l|}{ Improvement score } & \multirow{2}{*}{ Paired "t"value } \\
\cline { 2 - 5 } & \multicolumn{2}{|l|}{ Pre-test } & \multicolumn{2}{l|}{ Post test } & \\
\cline { 2 - 5 } & Mean & $\begin{array}{l}\text { Standard } \\
\text { deviation }\end{array}$ & Mean & $\begin{array}{l}\text { Standard } \\
\text { deviation }\end{array}$ & \\
\hline Knowledge & 8.1 & 1.372 & 11.6 & 2.741 & 6.535015 \\
\hline Practice & 8.2 & 1.704 & 12.35 & 2.207 & 9.916670 \\
\hline $\begin{array}{l}\text { Overall knowledge and } \\
\text { practice }\end{array}$ & 16.3 & 3.027 & 23.95 & 4.559 & 8.97 \\
\hline
\end{tabular}

Table - III The mean score 8.1, 8.2\&16.3 and standard deviation 1.372,1.704\&3.027 obtained in the pre- test and a mean score 11.6,12.35\& 23.95 and standard deviation 6.53, 9.91,8.97 were obtained in the post test for the level of knowledge and practice among postnatal mothers showed that there was a increases in mean and standard deviation after the administration of structured teaching programme for postnatal mothers

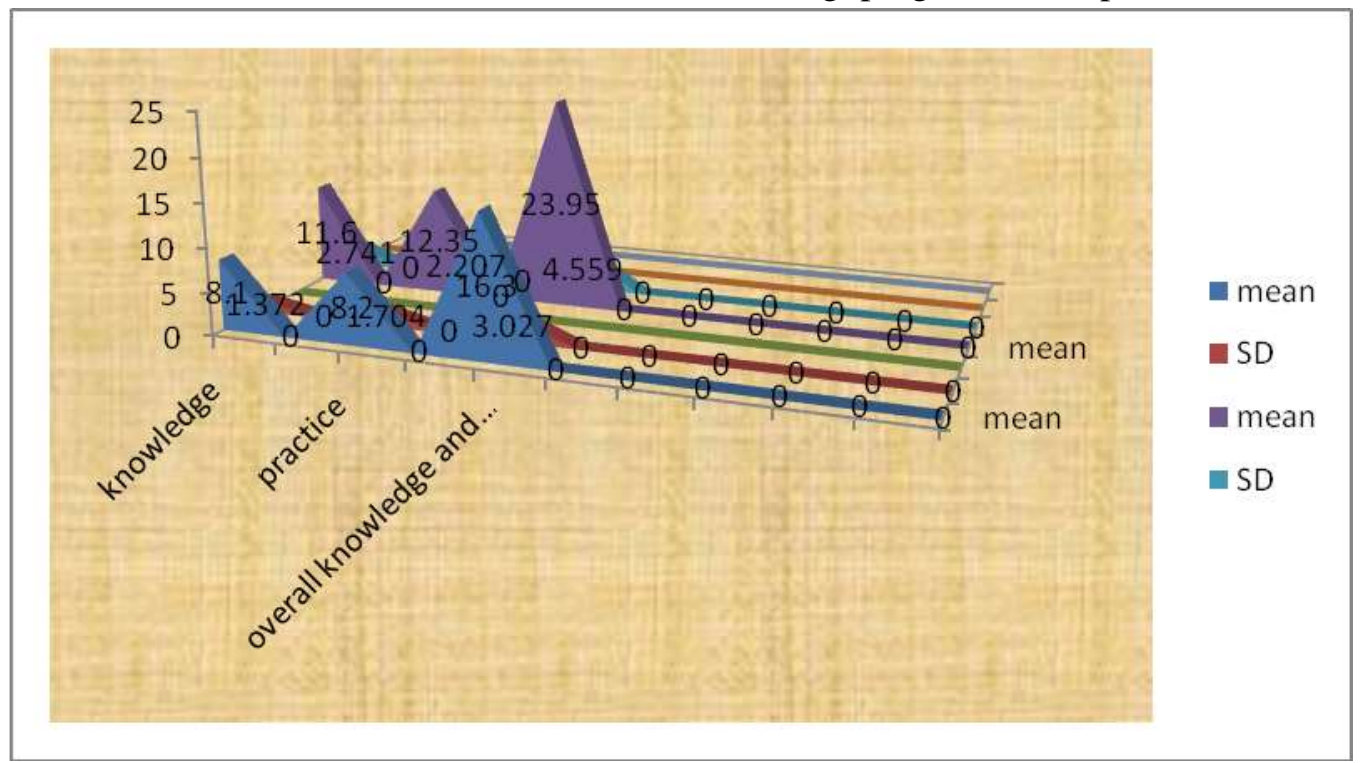

Fig III. Effectiveness of structured teaching programme on essential new born care among post natal mothers 


\section{CONCLUSION}

The present study revealed improvement in the level of knowledge and level of knowledge on practices related to essential new born care after administering the health education programme. It was proved that direct education can lead to increase in the level of knowledge and level of knowledge on practices related to essential new born care so that can prevent mortality and morbidity rates.

Still some of the demographic variables are not significant with the mother's knowledge. Irrespective of demographic variables, the post natal mothers improved their knowledgeafter receiving structured teaching programme. Hence, direct education has a bearing and can bring about improvement of their knowledge and change in a desirable behaviour.

\section{REFERENCES}

1. StephonW.ElizabathR.Research priorities to improve global forum for health research. Mexico 2004.

2. ParulDutta .Paediatric Nursing. ( $8^{\text {th }}$ edition). New delhi: Jaypee brothers publishers $2008 ; 110-113$.

3. Hocken berry and Willson ,Wong'sNursing Care of Infants and Children.( $8^{\text {th }}$ edition.). New Delhi: Elservier publishers 2005 : 200-204.

4. Belsey, M.(2000), global overview of Newborn health, summary of oral report to Director General of WHO Executive board.

5. World health organization. Essential Newborn Care (2011). A Report of technical working Group. Geneva.

6. Park .k preventive and social medicine, $22^{\text {nd }}$ edition,Jabalpur,Bhannot,2007 451-455.

7. Abraham (2001). A Text Book of Paediatrics. (1 ${ }^{\text {st }}$ edition). Singapore: Mc. Graw Hill international company.

8. Achars (2001). Text Book of Paediatrics. $3^{\text {rd }}$ edition .India: orient Longman.

9. Adele Pillitery (2005). Child Health Nursing.(2n $2^{\text {nd }}$ edition.). Philladelphia; J.B.Lippincott Company Publishers.

10. Barett (1998). Paediatrics . (14 $4^{\text {th }}$ edition ) New York :Meridith Corporation.

11. Basavanthappa. B. T. (2006).Paediatric/Child Health Nursing. ( $1^{\text {st }}$ edition.). New Delhi: Ahuja publishing house.

12. Donnai. L. Wong (2002). Essentials of Paediatrics. (6 $6^{\text {th }}$ edition). New York: Mosby Westilike

13. Dorothy. R. Marlow (2000). Text Book of Paediatrics. (6 ${ }^{\text {th }}$ edition). London: W.B Saunders. 